\title{
0 uso dos Sistemas de Suporte à Decisão (SSD) visando à melhora da qualidade do conteúdo jornalístico
}

\section{RESUMO}

O paper realiza cruzamento entre as áreas de Ciências Sociais Aplicadas (Jornalismo), Ciência Cognitiva (Psicologia Cognitiva) e Ciências Exatas (Computação) analisando a possibilidade da construção de artefatos tecnológicos computacionais e do uso de Sistemas de Suporte à Decisão (SSD), que permitam ao jornalista melhorar seus processos de decisão e, por conseqüência, melhorar a qualidade do conteúdo informativo de relevância social produzido e distribuído por diversos meios de comunicação.

\section{PALAVRAS-CHAVE \\ jornalismo \\ tecnologia \\ tomada de decisão}

\begin{abstract}
This paper interrelates the areas of Applied Social Sciences (Journalism), Cognitive Sciences (Cognitive Psychology) and Exact Sciences (Computing Sciences) in the analysis of the possibility of the construction of computational technological artifacts and the use of Decision Support Systems (DSS), which might enable journalists to improve their decision-making processes and, consequently, the quality of the informative content of social relevance produced and distributed by various means of communication.
\end{abstract}

\section{KEY WORDS}

journalism

technology

decision-making
Os modelos de negócios no campo do Jornalismo consolidaram estruturas e organogramas, sendo replicados e massificados dentro das redações em todo mundo. Com a evolução, novos processos surgiram com a introdução de tecnologias e a incorporação das novas demandas informativas pela sociedade.

Esses dois fatores, principalmente, fizeram com que as rotinas de trabalho se tornassem mais complexas e o tempo de apuração e produção da notícia, pelos profissionais da informação, encurtassem drasticamente.

Apesar das mudanças econômicas e de todos os aparatos tecnológicos que estruturam os processos de produção e distribuição das notícias, o jornalista é, ainda, o fator diferencial no processo de elaboração do conteúdo informativo de relevância social, pois é através da decisão humana que as informações são escolhidas, editadas, produzidas, distribuídas e, finalmente, entendidas pelo receptor.

Em toda essa cadeia informativa, o jornalista tem como objetivo tomar decisões para que o resultado do seu trabalho seja satisfatório, ou seja, desde a elaboração da pauta até a escolha de fonte, o jornalista tem de levar em consideração uma série de fatores para tomar suas decisões. Um dos objetivos dos making decision é chegar-se a melhor decisão possível dentro das condições oferecidas. Esse processo de decisão se utiliza de diversas "estratégias", como a heurística, para a tomada de decisão.

Porém, também o que chama bastante atenção é a questão do ambiente que envolve o tomador de decisão. Alguns aspectos do comportamento relacionado à decisão humana é a flexibilidade com que indivíduos respondem a uma ampla variedade de condições. Julgamentos preferenciais, estabelecimento de incertezas e escolhas entre caminhos de ações alternativos, todos podem ser afetados pela menor mudança no ambiente. Em uma redação jornalística, essas condicionantes estão bem presentes.

Essas diferenças podem ser minimizadas com usos de tecnologias computacionais que suportam os processos de decisão. Uma dessas vertentes tecnológicas são os Sistemas de Suporte à Decisão (SSD). Os SSD são soluções tecnológicas baseadas em sistemas computacionais que podem ser usados no suporte a complexos processos de tomada de decisão e resolução de problemas.

\section{Processos de decisão: 0 homem e a lógica}

Os processos de decisão do ser humano estão imbricados com os princípios da Lógica, onde se estabelece as bases da razão humana.

\author{
Walter Teixeira Lima Junior \\ Professor do Programa de Pós-Graduação da Cásper Libero/SP/BR \\ digital@walterlima.jor.br
}


Uma ciência é qualquer corpo organizado de conhecimento que possui princípios. Os primeiros princípios de qualquer ciência são aquelas verdades fundamentais em que se apóia e em que todas as suas atividades se baseiam. A lógica, como ciência, tem seus princípios fundamentais, mas a lógica guarda uma relação única com todas as outras ciências porque os primeiros princípios da lógica aplicam-se não apenas à lógica, mas a todas as outras ciências. $\mathrm{Na}$ verdade, suas bases são mais abrangentes, porque se aplicam à razão humana como tal, embora isso deva ser exercitado (Mclnerny, 2006, p.46).

Um sistema lógico é um conjunto de axiomas e regras de inferência que visam representar formalmente o raciocínio válido. Nesse ponto, os processos de decisão se encaixam. Um dos objetivos dos making decision é chegar-se a melhor decisão possível dentro das condições oferecidas.

Tradicionalmente, lógica é também a designação para o estudo de sistemas prescritivos de raciocínio, ou seja, sistemas que definem como se "deveria" realmente pensar para não errar, usando a razão, dedutivamente e indutivamente. A forma como as pessoas realmente raciocinam é estudado nas outras áreas, como na psicologia cognitiva. Como ciência, a lógica define a estrutura de declaração e argumento e elabora fórmulas através das quais estes podem ser codificados. Implícita no estudo da lógica está a compreensão do que gera um bom argumento e de quais os argumentos que são falaciosos.

A lógica filosófica lida com descrições formais da linguagem natural. A maior parte dos filósofos assume que a maior parte do raciocínio "normal" pode ser capturada pela lógica, desde que se seja capaz de encontrar o método certo para traduzir a linguagem corrente para essa lógica (Wikipedia, 2009).

\section{Processos de decisão}

O conceito de decisão (do latim de-cidere, "separar, cortar") indica um processo de redução das possibilidades de ação e, com tal, representa um dos núcleos mais problemáticos da racionalidade ocidental. $\mathrm{Na}$ medida em que evoca uma relação entre a razão e ação, a decisão se reveste das interrogações sobre os fundamentos da atuação humana (Maldonado, 2005, p.76-82).

O filósofo grego Aristóteles (384-322 a.C.), um dos maiores pensadores de todos os tempos e considerado o criador do pensamento lógico, e os escolásticos ${ }^{1}$ foram os primeiros a delinear uma correlação conceitual entres os processos de decisão e a escolha.

Se Aristóteles definiu a escolha como "apetição deli- berada que concerne coisas que dependem de nós", Spinoza ${ }^{2}$ identificou a decisão com o desejo ("determinação do corpo") que pode ser deduzido das leis do movimento e da quietação. Livre ou determinada, o fato é que a decisão invariavelmente é concebida pelos filósofos como o ato que discrimina entre alternativas possíveis. Isto é, ato que antecipa e planeja, e que condiciona o futuro mediante a determinação de possibilidades efetivas (Wikipedia, 2009).

Para Mauro Maldonado, as teorias atuais sobre a decisão racional consideram elevado o papel da incerteza, da falibilidade e do risco. Herbert Simon (1983) definiu a atividade do tomador de decisões nos seguintes termos:

A teoria clássica é a teoria de um homem que escolhe entre um número fixo de alternativas, a cada uma das quais estão associadas conseqüências. Mas, quando entre tomador de decisões e ambiente objetivo intervêm sua percepção e seus processos cognitivos, esse modelo demonstra toda sua inadequação. Precisamos de uma descrição do processo de escolha que reconheça que as alternativas não são dadas, mas devem ser buscadas, uma descrição que leve em conta a árdua tarefa de determinar que conseqüências cada alternativa acarreta (Maldonado, 2005, p.76-82).

Porém, opondo-se às teorias fundamentadas na maximização, Simon propõe - de acordo com outros psicólogos cognitivos - uma teoria da racionalidade limitada, em que os limites cognitivos induzem o tomador de decisões a recorrer a um modelo simplificado do mundo com o qual interage. O critério fundamental desta teoria é noção de satisficing, cujo pressuposto é de que o indivíduo trabalha tendo em vista um resultado satisfatório, embora não necessariamente ótimo.

Utilizando o conceito de racionalidade limitada, "a recorrer a um modelo simplificado do mundo com o qual interage", no processo decisório da escolha das fontes jornalísticas, encaixamos o trabalho do jornalista, que procura, geralmente, um "resultado satisfatório, embora não necessariamente ótimo". Essa sistemática tem afetado a qualidade do jornalismo praticado e, conseqüentemente, sua credibilidade.

\section{Processos de decisão na profissão: as fontes são esco- Ihidas pelo jornalista}

No modelo atual de negócio, em grande parte dos veículos de comunicação - desde pequenos até conglomerados de mídia - o jornalista (repórter), ou na função de editor, é o elo da cadeia de produção industrial da notícia. É ele que decide o que entra ou não entra na formação do conteúdo jornalístico.

Qual o objetivo do jornalista? Para obter algum resultado, o jornalista trabalha com a informação, que 
é sua matéria-prima. Para existir notícia é necessário primeiro que haja uma informação de interesse universal. O consumidor da notícia pode não estar interessado no produto final da notícia, na sua embalagem ou conteúdo ideológico, mas quer obter a informação que ela deve obrigatoriamente ter. A notícia é a matéria prima do jornalismo, pois somente depois de conhecida ou divulgada, é que os assuntos aos quais se refere podem ser comentados, interpretados e pesquisados (Lage, 2001).

Vários processos decisórios, incluídos na cadeia de produção da notícia, estão em poder do jornalista, como o da seleção de temas a serem abordados; a escolha de fontes de informação (selecionar e qualificar como interlocutor válido); o questionamento da fonte; a coleta de dados (depoimentos); a estrutura das informações conforme contexto; a utilização de técnicas de produção (exemplo: roteiro para uma reportagem de televisão) e como o conteúdo será entregue ao consumidor. Porém, é na produção da pauta $^{3}$ que a procura por fontes é iniciada.

O processo de produção de qualquer tipo de conteúdo jornalístico começa com a elaboração da pauta. Essa fase consiste na listagem dos principais objetivos a serem alcançados na confecção da matéria noticiosa, como hipóteses a serem verificadas e angulação que a notícia irá adotar (Lage, 2001).

Na realização da matéria, cabe ao jornalista a tarefa de encontrar fontes que tenham credibilidade, atualidade e que valide a informação obtida. A fonte é importante para fornecer veracidade à matéria jornalística e ajudar na compreensão do fato pela sociedade. Para que esse objetivo seja alcançado, o profissional deve verificar se a fonte é confiável, se ele pode verificar a informação por ela passada, avaliando a maturidade (se tem experiência consolidada no assunto abordado pela pauta), se tem proximidade com o assunto, se é a melhor autoridade (no sentido de conhecer o assunto) e se é possível saber o que outra fonte pensa da fonte contatada.

\section{Importância de automatizar os processos de decisão}

O processo de decisão do jornalista na escolha de uma fonte, em muitas situações, sem perceber conscientemente, é realizado mentalmente, fazendo julgamentos e ou tomando decisões. A elaboração desses processos decisórios são casos de estudo, em geral, desde a década de 50, do século passado.

Os modelos mais antigos de como as pessoas tomam decisões são referidos como "Teoria Clássica da Decisão". Segundo Robert Sternberg, a maioria desses modelos foi delineada por economistas, por estatísticos, por filósofos, não por psicólogos (Sternberg,
2000, p.340).

O modelo alternativo apontado por Sternberg é a "Teoria da Utilidade Esperada Subjetiva", quando o objetivo da ação humana é buscar o prazer e evitar a dor. No caso do jornalismo, a questão dos prazos, adequado ao interesse editorial do veículo e a busca por dar credibilidade a matéria, são variáveis que fazem parte do processo. De acordo com essa teoria (Sternberg, 2000, p.341), ao tomar decisões, as pessoas procurarão maximizar o prazer (referido como utilidade positiva) e minimizar a dor (referida como utilidade negativa). Assim fazendo, entretanto, cálculos tanto da utilidade subjetiva (baseada nas ponderações da utilidade julgado pela pessoa, em vez de critérios objetivos), quanto da probabilidade subjetiva (baseada nas estimativas de probabilidade da pessoa, em vez de cômputos estatísticos objetivos).

A “Teoria da Utilidade Esperada Subjetiva" está baseada na crença de que as pessoas procuram alcançar decisão bem racionais baseadas em:

1. Consideração de todas as alternativas possíveis

2. Uso da quantidade máxima de informações

3. Ponderação dos custos (risos) e dos benefícios potenciais de cada alternativa

4. Cálculo de probabilidade

5. Um grau máximo de raciocínio lógico, baseado na consideração de todos os fatores supramencionados (Sternberg, 2000, p.341).

Porém, essa teoria é questionada devido a que tomamos muitas decisões sem levar em consideração todos esses itens. No caso do jornalismo, uma variável importante para que não tenhamos condições de ponderar todos os itens acima é a questão do tempo escasso para a produção do material jornalístico.

\section{Na realização da matéria, cabe ao jornalista a tarefa de encontrar fontes que tenham credibilidade, atualidade e que valide a informação obtida.}

Por isso, no início dos anos 50, pesquisadores começaram a questionar a noção de racionalidade limitada. Eles reconheciam que, nós, os seres humanos, nem sempre tomamos decisões ideais e que, via de regra, incluímos considerações subjetivas em nossas decisões, mas também sugerem que nós não somos inteiramente racionais ao tomar decisões.

O Prêmio Nobel de Economia, Herbert Simon ${ }^{4}$, em 
1957, sugeriu que nós não somos necessariamente irracionais, mas que demonstramos uma racionalidade limitada, ou seja, somos racionais, mas dentro de limites. Ele denominou essa estratégia de Satisficing.

Com o Satisficing, não consideramos todas as opções possíveis e, então, calculamos de maneira cuidadosa quais do universo inteiro de opções maximizarão nossos ganhos e minimizarão nossas perdas. Mais exatamente, consideramos as opções uma por uma e depois selecionamos uma opção, tão logo encontremos uma que seja satisfatória, ou simplesmente aquela considerada boa o suficiente para satisfazer nosso nível mínimo de aceitabilidade.

Um tomador de decisão pode decidir ajustar o nível mínimo considerado adequado para satisficing se achar que um número desconfortavelmente alto de opções não conseguiu alcançar o nível mínimo de aceitabilidade (Sternberg, 2000, p.342).

\section{A questão do contexto}

A obra The adaptive decision maker (Payne; Bettman; \& Johnson, 1993) afirma que um dos mais fascinantes aspectos do comportamento relacionado à decisão humana é a flexibilidade com que indivíduos respondem a uma ampla variedade de condições. Julgamentos preferenciais, estabelecimento de incertezas e escolhas entre caminhos de ações alternativos, todos podem ser afetados pela menor mudança no ambiente.

\section{A experiência em um domínio de decisão também pode impactar a freqüência e quanto recente com que as estratégias disponíveis têm sido usadas, consequentemente afetando a acessibilidade de várias estratégias.}

Essa ponderação é importante para esse trabalho, pois parte-se da premissa que os jornalistas em questão, que escolhem fontes para as suas matérias, necessariamente trabalham em grandes veículos de comunicação de massa. Portanto, estão sempre em um ambiente de redação. Esse fator é fundamental para que o profissional faça certas escolhas em detrimento de outras, por exemplo, ao consultar um colega de trabalho sobre uma determinada fonte. As decisões não são feitas em um vácuo social. Muitos fatores sociais influenciam a tomada de decisão (Tetlock, 1985). Para Payne, Bettman
\& Johnson (1993), as três grandes classes de fatores que influenciar que estratégia é utilizada para resolver um particular problema de decisão: características do problema, características da pessoa e as características do contexto social.

Em um nível psicológico detalhado de análises, esses três tipos maiores de fatores influenciam a estratégia de escolha afetando a disponibilidade, acessibilidade, processabilidade e a percepção dos benefícios de várias estratégias de decisão. Por um momento, o conhecimento precedente, obtido através da experiência ou treinamento, determinará que estratégias estão disponíveis para tomar uma decisão na memória. A experiência em um domínio de decisão também pode impactar a freqüência e quanto recente com que as estratégias disponíveis têm sido usadas, consequentemente afetando a acessibilidade de várias estratégias. Isso é, experiências com estratégias afetarão a probabilidade de reutilizar uma determinada estratégia (processabilidade). Finalmente, as características do contexto social podem influenciar a relativa importância de tais fatores como a justificativa de umas decisões em determinadas seleções de estratégias (Payne; Bettman \& Johnson, 1993, p.4).

\section{Tomador de decisão adaptativo}

O jornalista é um profissional preparado, teoricamente, para trabalhar em redação e, mais recentemente, também para realizar o seu trabalho como free-lancer ou microempresário. É uma variedade de ambiente de trabalho, com a redação podendo ser em uma emissora de televisão com boa estrutura física e tecnológica, como a Rede Globo, ou do interior de um Estado com menor renda per capta, portando, com menor capacidade estrutural. Essa condição também vale para redações de jornais, revistas, rádios e internet. Com esse amplo espectro, o profissional do jornalismo tem de ter uma capacidade de adaptação ao ambiente e as rotinas de trabalho contidas nele. É o fator denominado de contexto. São essas rotinas que estabelecem os atributos e variáveis que devem ser levadas em consideração na produção de uma matéria. Essa adaptação segue no processo de decisão para a escolha de uma pauta ou fonte, por exemplo. A adaptação passa a ser um componente constante no processo de decisão.

Os tomadores de decisão não utilizam somente informação extraída do problema original para decidir qual estratégia utilizar, mas também usam informação que eles já têm identificado e explorado, que forneceram caminhos promissores e ajudarão nos futuros processamentos. Pessoas constroem estratégias no percurso, assim como, seleciona entre as estratégias de decisão uma prioritária, como demonstram os pesquisadores Payne, Bettman \& Johnson (1993, p.190):

1 - Independente das estratégias, a ordem de atenção sobre os fatores sofrerá uma forte influência na pre- 
ferência dos itens que são observados;

2 - O mais construtivo é o uso de estratégia, o mais importante são os fatores de contexto em determinadas decisões;

3 - Processos construtivos estarão mais, provavelmente, nos problemas de decisão que envolve pequena prioridade e que são cheios de estresse.

Entre os fatores que contribuem para insucesso do tomador de decisão adaptativo estão a dificuldades em avaliar tarefas e fatores de contexto; não conhecimento de estratégias apropriadas e dificuldades em avaliar o esforço e/ou precisão de uma estratégia em uma particular situação. Somando-se a esses fatores, encontramos outras questões, como um ambiente de trabalho estressante, dificuldade em acessar tecnologias de informação computacionais, problemas de representação da realidade e, mais geralmente, qualquer aspecto de uma decisão que demanda a utilização de muita memória (Payne; Bettman \& Johnson, 1993, p.216).

\section{Estresse como fator de baixa cognição}

Outro fator importante para uma tomada de decisão com baixa eficiência é a questão das condições de trabalho oferecidas ao jornalista. Com o contínuo "enxugamento" das redações, várias rotinas foram fundidas e muitos profissionais foram obrigados a assumir tarefas de funções que foram extintas. Também existe a questão do trabalho para grandes corporações.

\section{Nesse contexto de produção, a tomada de decisão sobre várias influências, principalmente, do estresse, baixa o nível de percepção humana e,} consequentemente, a absorção de
informaçóes importantes para 0
processo de decisão.

A atual lógica de mercado, em um mundo globalizado, em muitos casos, sobrepõe o interesse público em detrimento dos interesses das grandes corporações. Esses interesses, infelizmente, têm a anuência de alguns editores ou donos de grandes veículos de comunicação. No meio desse jogo, estão os repórteres, profissionais pagos para produzir informações relevantes para a sociedade, mas que se deparam com forças intimidatórias e economicamente fortes e influentes, limitando o posicionamento dos profissionais face as suas fontes de informação.

Ao lado das fontes, jornalistas e redações têm de lidar igualmente com as pressões e constrangimentos oriundos dos proprietários dos meios, dos anunciantes, dos lobbies e interesses políticos, sem esquecer a própria cultura profissional dos jornalistas (Soloski, 1993).

Nesse contexto de produção, a tomada de decisão sobre várias influências, principalmente, do estresse, baixa o nível de percepção humana e, consequentemente, a absorção de informações importantes para o processo de decisão.

Existem muitas variáveis que influem no processo de tomada de decisão para a escolha de uma fonte jornalística. Muitas podem ser eliminadas ou minimizadas com a reestruturação de rotinas e treinamento intensivo e constante de jornalistas. Porém, a realidade econômica e cultural, muitas vezes, não comporta tais alternativas. Muitos dos erros cometidos em processos de produção de notícias são recorrentes há décadas, como apontam estudiosos do setor.

A automatização de alguns processos minimizaria alguns desses erros. Entretanto, não considero que possa existir um sistema complexo que controle toda a cadeia decisória da escolha de fontes jornalística, por exemplo. Mas, sistemas, menores e consistentes, de apoio à tomada de decisão, podem ser úteis na busca da melhora qualitativa no trabalho dos jornalistas.

Uma dessas vertentes tecnológicas são os Sistemas de Suporte à Decisão (SSD). Os SSD são soluções tecnológicas baseadas em sistemas computacionais que podem ser usados no suporte a complexos processos de tomada de decisão e resolução de problemas. Esses sistemas têm origem em duas principais áreas de pesquisa - os estudos teóricos de tomada de decisão organizacional (Simon, Cyert, March e outros) conduzidos pelo Carnegie Institute of Technology durante o final dos anos 50 e início dos anos 60 e o trabalho técnico (Gerrity, Ness e outros) executado no MIT nos anos 60.

O desenho das ferramentas do clássico SSD é composto dos componentes:

a) capacidade de gerenciamento de sofisticados bancos de dados, com acesso a dados internos e externos, informação e conhecimento;

b) poderosas funções de modelagem acessadas por um sistema modelo de gerenciamento;

c) poderosa, mas simples interfaces, com funções gráficas. (Shim et al, 2002, p.1).

Os SSD têm se desenvolvido gradualmente desde o início dos anos 70. Depois de três décadas, os SSD têm tido amplas ou estreitas definições, enquanto outros 
sistemas têm emergido para assistir tipos específicos de tomadas de decisão em função de específicos tipos de problemas. Pesquisadores da área têm tipicamente focados em como a tecnologia da informação pode melhorar a eficiência com que o usuários toma uma decisão e como pode melhorar a eficácia dessa decisão (Pearson \& Shim, 1995, p.141-158).

O original conceito de SSD foi mais claramente definido por Gorry e Scott Morton (1971, p.50-70), integrado com as categorias de gerenciamento de atividades de Anthony (1965) e a descrição dos tipos de decisão de Simon (1960). Anthony descreveu as atividades de gerenciamento como consistir do planejamento estratégico (decisões executivas que levam em consideração todas as missões e metas), controle de gerenciamento (gerência média que guia a organização aos objetivos) e controle operacional (primeira linha de supervisores direcionando tarefas específicas).

Já Simon descreveu os problemas de decisão quando existir a passagem de uma continuidade programada (rotina, repetição, boa estrutura, fácil resolução) para não-programada (nova, estrutura pobre, difícil resolução). Gorry e Scott Morton (1971) combinaram com as atividades de gerenciamento de Anthony (1965) e as descrição de decisões de Simon (1960), usando os termos estruturados, desestruturados e semi-estruturados, do que programado e não-programado. Eles também usaram as descrições dos processos de tomada de decisão de Simon, como inteligência, design e escolha. Nessa estrutura, a inteligência é compreendida da busca por problemas, o design envolve o desenvolvimento de alternativas e a escolha consiste da análise das alternativas e escolha de uma delas para implantação. Um SSD foi definido como um sistema de computador que negocia com um problema onde pelo menos alguns estágios estão semi-estruturados ou desestruturados. Um sistema de computador poderia ser desenvolvido para negociar com uma porção estruturada de um problema do SSD, mas o julgamento do tomador de decisão seria carregado na parte desestruturada, a partir disso, constituiria um sistema homem - maquina, resolução de problemas.

Portanto, cada sistema necessita de um tipo de modelagem. Gorry and Scott Morton (1971) também argumentam que ambos os tipos de informação, estruturada e desestruturada, necessitam de diferentes modelos em um ambiente SSD. A natureza da informação desestruturada necessita de diferentes sistemas de databases do que necessários em ambientes operacionais. Banco de dados operacionais e linguagens de flexíveis são necessários. Similarmente, a natureza da informação desestruturada do processo de decisão implica na necessidade para ambientes de modelagem flexível.

\section{Considerações finais}

Uma das questões tratadas nesse trabalho é sobre a teoria da racionalidade limitada, em que os lim- ites cognitivos induzem o tomador de decisões a recorrer a um modelo simplificado do mundo com o qual interage. Essa questão pode ser constatada na cadeia de produção da notícia, onde vários processos decisórios estão em poder do jornalista, como o da seleção de temas a serem abordados Outra questão importante para a que uma tomada de decisão tenha baixa eficiência, é a que toca nas condições de trabalho oferecidas ao jornalista. Com o contínuo "enxugamento" das redações, por adoção de modelos de negócios à base do downsizing, várias rotinas foram fundidas e muitos profissionais foram obrigados a assumir tarefas de funções que foram extintas. Nesse ambiente de produção, a tomada de decisão sobre várias influências, principalmente, do estresse, que baixa o nível de percepção humana e, conseqüentemente, a absorção de informações importantes para o processo de decisão. Muitas variáveis que influenciam no processo de tomada de decisão para a escolha de uma fonte jornalística. As empresas jornalísticas tentam eliminar ou minimizar muitas delas com a reestruturação de rotinas e treinamento intensivo e constante de jornalistas. Entretanto, a realidade econômica e cultural, muitas vezes, não permite que tais alternativas sejam introduzidas. Muitos dos equívocos cometidos em processos de produção de notícias são recorrentes há décadas, como apontam estudiosos do setor. Portanto, a automatização de alguns processos minimizaria alguns desses erros. Entretanto, o estudo não considera a hipótese de que possa existir um sistema complexo que controle toda a cadeia decisória da escolha de fontes jornalística, por exemplo. Porem, sistemas computacionais, menores e consistentes, de apoio à tomada de decisão, podem ser úteis na busca da melhora qualitativa no trabalho dos jornalistas, como os Sistemas de Suporte à Decisão (SSD) — FAmecos

\section{NOTAS}

1 A Escolástica (ou Escolasticismo) é uma linha dentro da filosofia medieval, de acentos notadamente cristãos, surgida da necessidade de responder às exigências da fé, ensinada pela Igreja, considerada então como a guardiã dos valores espirituais e morais de toda a Cristandade. Por assim dizer, responsável pela unidade de toda a Europa, que comungava da mesma fé. Disponível em: <http://pt.wikipedia. org/wiki/Escol\%C3\%A1stica>. Acesso 13 abr 2009.

2 Benedictus de Spinoza (Amsterdã, 24 de Novembro de 1632 - Haia, 21 de Fevereiro de 1677), forma latinizada de Baruch de Spinoza (em hebraico: (הזוניפש דורב , também conhecido por Bento de Espinosa, foi um dos grandes racionalistas da filosofia moderna, juntamente com René Descartes e Gottfried Leibniz. Considerado o fundador do 
criticismo bíblico moderno. Disponível em: <http:/ / pt.wikipedia.org/wiki/Spinoza>. Acesso 13 abr 2009.

3 Primeiro roteiro para a produção de textos jornalísticos e material iconográfico. In: Manual de Redação da Folha de São Paulo. São Paulo: PubliFolha, p.46, 2001.

4 Herbert Alexander Simon, economista Norte americano, nasceu em Milwaukee, Wisconsin em 15 de Agosto de 1916. Doutorado em Ciências Políticas pela Universidade de Chicago em 1943 onde foi assistente da cadeira de Investimento, entre os anos de 1936 e 1938, anos em que colaborou com a Universidade da Califórnia. De 1942 a 1949 lecionou no Instituto tecnológico do Illinois, transitando nesse último ano para a Universidade de Carnegie-Mellon, em Pittsburg, onde foi titular da cadeira de Administração e Psicologia até 1965 e regente da cátedra de Informação e Psicologia. Antigo colaborador da Rand Corporation, consultor do Governo dos EUA, da NASA, ex-diretor do conselho de pesquisas de Ciências Sociais. Laureado com o Prêmio Nobel de Economia em 1978, pelas suas pesquisas realizadas na área de "tomada de decisões no interior das organizações econômicas". Segundo a sua teoria, a empresa deve ser encarada como um sistema de decisões onde o indivíduo é responsável pela tomada das mesmas. Segundo ele, o planejamento é necessário a todos os níveis e é o substrato da racionalidade no comportamento administrativo. Membro da Academia Nacional de Ciências dos EUA e da sua congênere Iugoslava e da Sociedade Americana de Filosofia.

5 Professor Honorário da Universidade de Tiangin, Doutor Honorário em Leis pelas Universidades de Chicago, McGill, Michigan, Pittsburg; em Filosofia pela Universidade de Lund e em Ciências Econômicas pela Universidade Erasmus. Galardoado com os prêmios A. M. Turing, em 1975, ao lado de Allen Newell, e Procter em 1980.

6 Disponível em: <http://www.citi.pt/educacao_ final/trab_final_inteligencia_artificial/herbert_ simon.html. Acesso 13 abr 2009.

\section{REFERÊNCIAS}

ANTHONY, R. N. Planning and control systems: a framework for analyses. Cambridge: Harvard University Graduate School of Business Administration, 1965.

GORRY, G. A; MORTON, M. S. Morton. A framework for management information systems. In: Sloan
Management Review, Vol 13, nº 1, p.50-70, 1971.

LAGE, Nilson. A reportagem: teoria e técnica de entrevista e pesquisa jornalística. Rio de Janeiro: Record, 2001.

MALDONADO, Mauro. Decisões que a razão desconhece. In: Scientific American Brasil, Ano 3 $\mathrm{n}^{\mathrm{o}} 33$, p.76-82,2005.

MCLNERNY, D. Q. Use a Lógica. Rio de Janeiro: Best Seller, 2006.

PAYNE, John W; BETTMAN, James R. \& JOHNSON, Eric J. The adaptive decision maker. New York: Cambridge University Press, 1993.

PEARSON, J. M \& SHIM, J.P. An empirical investigation into DSS structures and envirorments. Decision Support Systems, Vol 13, 1995.

STERNBERG, Robert J. Psicologia cognitiva. Porto Alegre: Artes Médicas, 2002.

SOLOSKI, John. O Jornalismo e o Profissionalismo: Alguns Constrangimentos ao Trabalho Jornalístico. In: TRAQUINA, Nelson (Org.) Jornalismo: questões, teorias e 'estórias'. Lisboa: Vega Sage, 1993.

SHIM, J.P et al. Past, present, and future of decision support technology. Paper apresentado na 30th Decision Sciences Institute Annual Meeting. New Orleans, 2002.

SIMON, H. A. The new science of management decision. New York: Haper Brothers, 1960.

WIKIPEDIA. Lógica. Disponível em <http:// pt.wikipedia.org/wiki/L\%C3\%B3gica>. Acesso 13 abr 2009. 